\title{
Implications of the Cooperative Study of Teacher Education for Libraries
}

\author{
W. E. Armstrong is coordinator, \\ Commission on Teacher Education, \\ American Council on Education, \\ $W$ ashington.
}

$T^{N}$ THIS paper I shall attempt briefly 1 to outline the Cooperative Study of Teacher Education with a view to indicating what it hopes to do, to describe some of its activities, and to point out what seem to me to be the implications for libraries and librarians. ${ }^{1}$ The study is an undertaking initiated by the Commission on Teacher Education of the American Council on Education for the purpose of improving the education of elementary and secondary school teachers. It is national in scope in that it touches all sections of the United States and involves practically all types of collegiate institutions and school systems. On the assumption that the greatest good to the greatest number would result from intensive work with a limited number of collegiate institutions and school systems, the commission selected twenty colleges and fourteen school systems to serve as a spearhead in an attack on broad problems of teacher education. This selection was made in June 1939, and the study will continue to January 1943.

The launching of this study was no

1 Those interested in a fuller statement concerning
the study will find the first four references listed
under ( $I$ ) at the end of this article helpful. accident, nor were its purposes left vague. A subcommittee of the Problems and Plans Committee of the American Council on Education had made a preliminary study which was published in 1937. In this report, the subcommittee recommended that "ample funds be secured to make possible a nationwide study which will have wise judgment on the part of a governing committee or commission, skilful staff direction, diversified problem studies and cogent interpretation of findings which will be translated into procedures in practice as rapidly as possible."2 This course called for a plan and a program that would bridge the gap between research findings and practice in the education of teachers at the pre-service and the inservice levels. As the commission has proceeded to develop a program in harmony with this charter, it has been guided by certain premises. The most important of these are:

I. Teacher education is comprehensive; that is, it relates to all aspects of the education of the teacher.

2. Teacher education is continuous. A program should concern itself with the teacher's educational needs from the time a decison is made to enter the profession until the teacher withdraws from it.

3. Procedures for the education of teachers must be based on conditions peculiar to the institution or school system. In other words, the commission should not seek to 
impose a plan or pattern on any unit with which it is associated.

The study, then, is not a study in the sense that an outside agency investigates for the purpose of recommending changes in procedures or shifts in functions of personnel. Nor is it a study in the sense that absolute answers will emerge at the end of the period. Certainly the commission and the cooperating institutions and school systems in the study expect certain evidence to emerge that will indicate the superiority of some practices over others. Such evidences will have to be interpreted, however, in terms of conditions which existed at the beginning and at the end of the study in a given situation. Little emphasis is being placed on "controlled" and "experimental" groups.

\section{Aims of the Study}

From what has just been said, it is easy to understand the major aim of the study. To state it simply, it is to improve teacher education practices generally at both the pre-service and the in-service levels. This broad aim will be realized only to the extent to which all organizations, agencies, institutions, and school systems in the country become a part of the program and lend their assistance to it. Promising practices are developing in most of the thirty-four cooperating groups and in many other institutions and school systems. The commission intends to encourage all these developments, to assist in refining procedures, and to facilitate their dissemination.

More specifically, the commission hopes to move in the direction of the following aims through the Cooperative Study of Teacher Education:

I. To broaden the concept of the scope of teacher education. In some institutions, the only group that concerns itself consciously with the education of teachers is the department of education or the school of education. In such institutions, psychology, methods, student teaching, and the like, often constitute the conscious scope of teacher education. The subject matter groups, if they concern themselves at all, teach special methods courses for students majoring in their specialties. Teacher education at the pre-service level, broadly conceived, will transcend departmental and even school lines.

Likewise, there is need for broadening the concept of teacher education at the in-service level. Most teachers read professional literature, participate in faculty meetings, and attend summer school. Some read widely in other areas, participate in forward-looking curriculum development programs, and concern themselves with community activities. Few teachers as individuals, and fewer school systems as such, see the need for continuing the education of the teacher along general cultural and social as well as strictly professional lines. The teacher as a teacher must operate within certain limits set by the experiences of the teacher as a person. Doubtless there is much room for the improvement of the education of the teacher as a teacher, but certainly this area is not neglected half so much as the educational needs of the teacher as a person.

2. To develop effective patterns of attack on the problems of teacher education. Many restless souls in collegiate institutions are conscious of practices which tend to hinder rather than facilitate the realization of broad educational purposes. They feel helpless to act because an attack through regularly constituted channels fails to reach the basic obstruction. A 
few higher institutions are finding effective ways of breaking through these obstructions. These ways must be tested further, refined, and finally described operationally for the benefit of others.

In the case of school systems, the situation has been little better. Administration, supervision, and teacher growth have not been any too well synthesized in most situations. Effective group thinking and planning are all too rare among teachers, supervisors and administrators. It is hoped that this study will disclose some helpful guides in this direction.

3. To establish a more effective working relationship among collegiate institutions and between such institutions and the school systems within their service areas. All colleges have their particular strengths and weaknesses. Different types of collegiate institutions possess strengths peculiar to those types: teachers colleges are strong in one respect, universities in another, and liberal arts colleges in another. Much is already being done to facilitate the sharing of promising practices among the institutions of a particular type, but much yet remains to be done to bring about a free flow of ideas from one type of institution to the other. Through conferences and other forms of cooperative activity the commission is lending assistance and encouragement to institutions within a given area to pool their efforts in their attack on problems.

The influx of pupils with less remote educational goals, and the introduction of new courses in the secondary schools have placed new demands on teachers. Furthermore, the tendency to place an elementary teacher with a group of pupils throughout the day, and to assign secondary school teachers to teach courses which cut across traditional subject matter boundaries, calls for teachers with broader and more functional knowledge. Social and economic changes also make new demands on teachers. It is too much to expect that these new elements will be recognized in the education of teachers unless college professors and public school people plan deliberately in that direction. In programs of curriculum development, the services of college professors are badly needed. Practically everyone realizes that public school people need the assistance that could be provided by collegiate institutions and that collegiate institutions need the help from the public schools in planning realistically for the education of teachers. Certainly, the cooperative study should expect to make some dent in this perplexing problem.

4. To refine techniques for the utilization of special types of services. Educators are familiar with conferences. On the whole, they are none too well pleased with the results. The dissatisfaction seems to lie in the lack of concreteness of the treatment of the problems under consideration and the lack of relationship between the conferences and the on-going programs of the participants. Likewise, educators are accustomed to visiting other situations where promising practices are reported to be in operation. Often these visits are planned in connection with some other trip, the purposes are vaguely conceived, the host makes no preparation for the visit, and the relation of what is seen by the visitors to the total program is not known. Consultation by experts on specific problems or on a total program is also becoming more and more common. Institutions and school systems desirous of such services are asking such questions as, "At what stage is a consultant most helpful ?" "How often should he come?" 
"How long should he stay?" "What preparation should be made for his visits?" "On how many problems should we ask him to consult?" These are some of the kinds of special services the cooperative study should help to refine, and these are some of the questions with reference to these services that we should seek to answer.

5. To improve procedures for the evaluation of programs of teacher education. Progress in the area of evaluation has been very rapid within the last half century. It has experienced three stages of development, viz., tests, measurements and evaluation. Testing began primarily with a trial of physical strength. Witness early tests of handgrip, which later shifted to such faculties as memory. Testing yielded to measurement. The major difference between the two was a quantitative one; that is, measurement simply tested more aspects of the individual. Neither paid very much attention to whether the thing to be measured was important. The purpose was to discover facts.

Within the past decade, measurement has again broadened into what is now called evaluation. It differs in two major respects from measurement. First, it is concerned with the aims, the hypotheses, and the procedures as well as the outcomes. Second, it utilizes evidence not commonly admitted in measurement. Especially in the field of teacher education, the problem is yet far from a satisfactory solution. The basic needs seem to be for a clearer statement of aims with reference to which evidence may be secured, and a refinement of techniques for collecting evidence. The cooperative study offers a splendid laboratory for work on this important problem.
Organization and Activities of the Study

With this set of aims, though it is far from comprehensive, I shall turn now to a brief description of some of the activities in which the groups and the commission are cooperatively engaged.

Each cooperating unit has organized for the study in its own way. In most cases there is a general planning committee which assumes responsibility for identifying the problems most urgent, planning ways of attacking these problems, and determining the kinds of services to be requested from the commission. The membership of this committee is usually drawn from various departments in colleges, and from different grade levels and subject matter interests in school systems. The most common practice is to designate the chairman of this committee as local coordinator of the study. From one-third to one-half of his time is usually freed to give sustained impetus to the activities outlined for him by the committee.

The staffs in these cooperating units have placed special emphasis on this study since September 1939. During this academic year just closing they have in most cases re-examined their aims and procedures for the education of teachers. This appraisal has brought to light in the collegiate institutions such problems as selection and guidance, general education, integration of professional education, child growth and development, arts, social understandings, service to the field, and the functional use of the library. Some are still in the discussion stage with reference to these problems, while others are forging ahead with programs of action.

The commission attempts to provide service to these units at the point of need. It has on its staff three field coordinators, each of whom is responsible for providing 
general consultant service and for determining needs for special services in roughly one-third of the cooperating units.

Because of early demands by these units the commission has made special staff provisions for service in certain areas. A service center for consideration of problems relating to child growth and development has been set up at the University of Chicago. Some fifteen to twenty psychologists have been busy in this center during the past year examining research findings in this field for the purpose of determining their possible use in the education of teachers. Next year it is expected that around twenty persons from the cooperating units will work in this center on plans for reorganizing their programs of child development in their own institutions. At the same time, the staff in this center and some of the psychologists who have worked in the center during the year 1939-40 will provide consultant service to institutions already working on this problem.

Associated with the center on child growth and development is a division on teacher personnel. A central staff person and a small number of special consultants on a part-time basis furnish counsel to cooperating units interested in this problem.

Evaluation is a third area for which special staff provision has been made. The central staff person and a cabinet of consultants are providing help to cooperating units on problems of evaluation relating to all aspects of teacher education.

The most recent addition to the staff is a person in charge of the clearing house service. It is the responsibility of this person to supervise the publications program and to clear information about promising practices to the cooperating units and to the field generally.

As problems arise which call for services that cannot be provided by the regular staff of the commission, special consultants are employed on a part-time basis. Such persons are now assisting collegiate institutions in the areas of social understandings, general education, and the integration of the professional program. Such services are, of course, provided only as the planning committees of institutions identify particular problems on which they need help. The commission has never urged an institution to consider a problem which the staff itself had not already identified.

\section{Relation of Commission to Study Units}

As has already been indicated, these special services are being provided to the cooperating units because this is thought to be the most effective way to serve the cause of teacher education generally. There is no thought on the part of the commission that it is conferring a favor on the cooperating units. Rather, it is asking these units to share the responsibility for testing certain procedures and putting into practice recent research findings. The response from these institutions is encouraging.

The chief danger in this spearhead approach is that others interested in teacher education may tend to await pronouncements from this study before making any attempts to improve their own programs. The commission is trying to avert this danger by encouraging all institutions, organizations, and agencies interested in any phase of teacher education to reexamine their programs, try out new procedures, and evaluate them. It is working closely with various associations, special subject matter groups, state officers of education, and accrediting associations.

What does such a program imply for college libraries and librarians? The 
answer, of course, must be in terms of the aims of the study.

\section{Librarian's Role}

If there is to be a broadened concept of education for teachers-the first aim of the cooperative study-libraries and librarians will have a role to play. The librarian is in a very strategic position, since, presumably, he is not interested in any particular area of learning. $\mathrm{He}$ is by the very nature of his position interested only in student learning. Perhaps the greatest contribution he can make to this learning will be through an interpretation of the function of the many types of subject matter in promoting growth. He may be of assistance by working closely with professors and students in their efforts to find the right place for books, the proper use of pictures, maps, and the like, the most effective use to be made of excursions, and the values of work experience in the development of real understandings. To be able to do this, he will, of course, have to know from experience how all these ways of learning operate. This means a broad knowledge of as well as about books, an understanding of the sources and uses of such newer material as motion pictures, slides, radio, many first-hand contacts with the world of affairs and things, and a genuine interest in the growth and development of human beings. Such a librarian will prove invaluable to an institution whose faculty as a whole is engaged in the process of redefining the scope of teacher education.

While we are thinking about the materials that furnish the basis for educational experience, it might be well to consider the problem of coordinating these materials. Film and related services are being developed in many collegiate institu- tions. In some cases, special bureaus are being set up to handle these materials, in others cases they are under the direction of the extension division, while in some the library coordinates them. Likewise, curriculum laboratories are being organized under various systems of management. In a few institutions organized plans for field experiences and excursions are being developed. The problem here is to find a satisfactory way to coordinate such services. Should the science professor, for instance, have to consult the librarian for books his students will need, the motion picture adviser for materials in that area, and the specialist in excursions for help with that type of experience? If the answer is "no," then the librarian has a function to perform, for a comprehensive program of teacher education will require an increasingly greater number of types of materials. This does not necessarily mean that the librarian will need to develop a highly centralized system of control. On the contrary, it may even mean a much greater decentralization of housing. It does mean a coordination of function.

The cooperative study, as the name implies, places stress on cooperative planning. It is at this point that it probably has the greatest implications for librarians. As new patterns of attack on problems are developed in collegiate institutions they tend to cut across subject matter lines. They also tend to bring together at the planning stage all persons who will be involved in carrying out these plans. $\mathrm{Li}$ brarians are thereby becoming very important members of the major committees engaged in planning courses. In other words, this cooperative planning at the origin of things tends to bridge the gap between the professor and the librarian. Both are contributing to mutually accepted 
goals in their own special ways. The librarian helps to develop the purposes and to point out the kinds of materials that are available to promote these purposes. The professor serves to stimulate the student and to make the formal evaluation of the cooperative effort. By being a part of the planning process the librarian may be of much greater service to the students as they request help on their problems. Participation in planning also makes the librarian a much more intelligent purchaser of books and other materials.

\section{Materials to Enrich School Programs}

The third aim, viz., the establishment of a more effective working relationship between collegiate institutions and school systems, also has important implications for the library. School systems, both large and small, are searching for materials to enrich their programs. One university reports that it has received hundreds of requests for lists of free and near-free materials, as well as suggested approaches to other problems such as the organization of a library. The American Library Association has had some valuable experience with these free and near-free materials. How can such experience be made known to school systems? In increasing numbers, college professors are going out to work with schools on curriculum problems. Invariably changes brought about as a result of this service create needs for more materials. State departments of education and accrediting associations are also assisting schools in curriculum development. Likewise, their efforts produce demands for materials. These schools need help in selecting materials, in utilizing local resources in building libraries, in organizing them for maximum service, and in obtain- ing access to materials they are unable to purchase. Libraries may render direct assistance by providing materials and suggestions for distribution during the academic year. Indirect help may be furnished by developing a model library as a part of the campus school for yeararound use, especially in the summer when teachers come in from the service area. As the schools enrich their programs and as the collegiate institutions establish closer working relations with school systems, the library, a most important part of the collegiate institution, will find opportunity for enlarging its scope of influence.

The library has led the way in a wider use of books in education. There is increasing evidence that it can and is leading the way in the use of other materials. All realize that there are many problems yet to be solved if the library is to be the heart of an institution. The cooperative study offers both an opportunity and a challenge to the staffs of all collegiate institutions to make a contribution to an important educational movement.

\section{References}

I. American Council on Education. Cooperation in the Improvement of Teacher Education. Washington. 1939.

Armstrong, W. E. "A Cooperative Study of Teacher Education." Curriculum Journal 10:257-6o, Oct. 1939.

The Teachers Colleges' Contribution to the Cooperative Study of Teacher Education. American Association of Teachers Colleges, 1940.

Bigelow, Karl W. "Accent on Cooperation." The Educational Record 21:188202, Apr. 1940.

2. Major Issues in Teacher Education. Washington, 1938, pp. 43-44. (American Council on Education Studies, Series I, Vol. II, No. 4.) 